\title{
LA POSICIÓN DE LOS ESTATUTOS DE AUTONOMÍA EN EL SISTEMA CONSTITUCIONAL (COMENTARIO A LA STC 31/2010 DE 28 DE JUNIO DE 2010) (*)
}

\author{
MARIBEL GONZÁLEZ PASCUAL \\ Profesora Visitante de Derecho Constitucional \\ Universidad Pompeu Fabra
}

\author{
SUMARIO \\ I. Las dificultades para determinar la posición \\ de los Estatutos de Autonomía en el sistema \\ constitucional \\ II. Los elementos definitorios de los Estatutos de \\ Autonomías \\ III. El papel de la Justicia Constitucional en el \\ sistema autonómico.
}

\section{LAS DIFICULTADES PARA DETERMINAR LA POSICIÓN DE LOS ESTATUTOS DE AUTONOMÍA EN EL SISTEMA CONSTITUCIONAL}

La sentencia del Tribunal Constitucional 31/2010, de 28 de junio, estaba llamada a ser una decisión clave en el desarrollo político-jurídico del Estado Autonómico. Solo el hecho de haber resuelto un recurso de inconstitucionalidad planteado contra más de la mitad de los artículos del Estatuto de Autonomía de Cataluña (EAC), la habría convertido en una sentencia fundamental. Pero, además, dicho Estatuto se enmarca en un proceso de reformas estatutarias que comenzó en el 2004 y que no ha terminado. Estas reformas han implicado el comienzo de una nueva etapa en el Estado Autonómico, caracterizada por la iniciativa e impulso de las Comunidades Autónomas (CCAA), provocando un aumento de las diferencias institucionales y competenciales entre Autonomías y poniendo de relieve que, para algunos de sus actores principales, el modelo autonómico precisa una profunda remodelación. Por tanto, resulta más apropiado referirse a un

(*) El presente trabajo se enmarca en el proyecto de I+D+I financiado por MICINN (Ref.DER200804499). Agradezco los valiosos comentarios de los profs. Rafael Bustos Gisbert y Alex Saiz Arnaiz. 
proceso de reforma del Estado de las Autonomías, que simplemente afirmar que se han modificado varios Estatutos de Autonomía (EEAA) ${ }^{1}$.

En dicho proceso la reforma del Estatuto de Autonomía de Cataluña (EAC) ha sido la pieza clave. Desde sus orígenes fue un proyecto muy ambicioso, que no ocultaba el descontento de las fuerzas políticas principales de Cataluña hacia el desarrollo del Estado Autonómico ${ }^{2}$ y que sirvió de modelo para otras autonomías, siendo el mejor ejemplo la reforma del Estatuto de Autonomía de Andalucía. No es por ello de extrañar que la posición de los EEAA en nuestro sistema constitucional se haya convertido en un tema absolutamente central ${ }^{3}$. De hecho, no se podría entender la sentencia 31/2010 sin tomar en consideración la postura que adopta el Tribunal Constitucional (TC) respecto de los Estatutos de Autonomía.

En general, no se cuestiona la posición de los EEAA frente a las normas autonómicas. Es una afirmación obvia que los EEAA están sometidos a la Constitución. Ahora bien, resulta altamente controvertido en qué medida el modelo territorial está realmente definido en la Constitución y, en consecuencia, qué papel le corresponde al TC. En otros términos, la desconstitucionalización de la estructura del Estado implicó que los EEAA jugasen un papel central en la configuración del Estado Autonómico. La parquedad de la Constitución respecto del modelo territorial, las disparidades entre EEAA y, en especial, la falta de acuerdo entre los actores políticos convirtieron al TC en un actor principal. De hecho se ha calificado a la jurisprudencia constitucional de elemento constituyente del Estado ${ }^{4}$. En consecuencia, los posibles límites materiales a la reforma estatutaria están en la Constitución tal y como ha sido interpretada por una ingente jurisprudencia, que ha tendido a la exhaustividad y el detalle. Cualquier intento de modificación sustancial del Estado Autonómico tiene que hacer acopio de esta jurisprudencia.

La reforma proyectada por el EAC partía de la idea de que la jurisprudencia había coadyuvado a la configuración del modelo autonómico sobre la base de la Constitución y los EEAA. De manera que si éstos se modificaban, la jurisprudencia debía adaptarse a los cambios forzosamente ya que uno de los dos pilares normativos del modelo constitucional habría variado. Por tanto, una de las cuestiones a dilucidar era la posición del TC frente a los EEAA.

Igualmente problemática ha sido la relación de los EEAA con las normas estatales. $\mathrm{Al}$ ser los EEAA parte del bloque de constitucionalidad, son un parámetro en las con-

1 Cruz Villalón, P., «La reforma del Estado de las Autonomías», REAF, n 2, 2006, pág. 77

2 Viver i Pi-Sunyer, C., La reforma de los Estatutos de Autonomía, en La reforma de los Estatutos de Autonomía, AA.VV., CEPC, Madrid, 2005, págs. 12 y ss.

3 La bibliografía acerca de la reforma de los EEAA empieza a resultar inabarcable. Aparte de la bibliografía citada en el trabajo, merece la pena consultar también AA.VV., Estudios sobre la reforma del Estatuto, IEA, Barcelona, 2004; Ortega Álvarez, L.; Martín Delgado, I. (Cood.), La reforma del Estado Autonómico, CEPC, Madrid, 2005, TornOs MAS, J., «La reforma estatutaria: un debate marcado por la posición constitucional de los Estatutos de Autonomía», RGDA, no 12, 2006; Bustos GisBert, R., «Las tensiones del estado autonómico ante el proceso de reforma estatutaria», Revista Jurídica de Castilla León (Número extraordinario), 2005; RoIG Moles, E., «La reforma del Estado de las Autonomías: ¿Ruptura o consolidación del modelo constitucional de 1978?, REAF, n 3, 2006.

4 Cruz Villalón, P., «La Constitución accidental», La democracia constitucional. Estudios en homenaje al Profesor Francisco Rubio Llorente, volumen II, AA.VV., CEPC, Madrid, 2003, pág.1174. 
troversias competenciales 5 . En consecuencia, las leyes estatales han de respetar las competencias autonómicas recogidas en cada Estatuto de Autonomía. Paralelamente, los EEAA deben respetar las reservas que la Constitución establece respecto de las leyes orgánicas. Asimismo algunas leyes estatales condicionan el alcance de la competencia estatutaria por imperativo constitucional o, incluso, estatutario. Esta relación también se ha producido en sentido inverso, siendo el caso más claro las cláusulas subrogatorias respecto de la Administración de Justicia. Más complejo, si cabe, es el supuesto de las leyes previstas en el art. $150 \mathrm{CE}$.

Por tanto, no cabe simplificar las relaciones entre el Estatuto de Autonomía y el conjunto de las leyes estatales con fáciles referencias al principio de jerarquía, pero resulta también insuficiente el principio de competencia ${ }^{6}$. Además, las Cortes Generales aprueban los EEAA y sus reformas mediante ley orgánica. De manera que, las leyes orgánicas no sólo condicionan el contenido posible de los EEAA sino que son, también, un elemento definitorio del propio Estatuto.

Precisamente la relación entre los EEAA y las leyes orgánicas es otro de los puntos centrales en la sentencia. En este sentido, no solo múltiples artículos del EAC impactaban directamente en materias reservadas a la ley orgánica en la Constitución ${ }^{7}$, sino que en la medida en que la posición de los Estatutos en el sistema constitucional era la clave de bóveda de la sentencia, el papel que se otorgase a las leyes orgánicas podía ser decisivo. No en vano, la inserción de las leyes orgánicas en el sistema autonómico y el papel del TC en el mismo son dos cuestiones estrechamente vinculadas.

Si se sitúa en el núcleo de la conceptualización de los EEAA a las leyes orgánicas, se amplía la capacidad de maniobra del TC, porque se encuentra ante una ley aprobada por un procedimiento particularmente complejo que solo juega «en contra» de la propia ley. De hecho, conforme a la doctrina mayoritaria acerca de las leyes orgánicas, el principio democrático no constriñe al TC, sino el alcance de la ley ${ }^{8}$ Por ese motivo, y porque analizar todas las cuestiones que la sentencia aborda sería un objetivo inalcanzable para un trabajo de esta extensión, las próximas páginas estudian críticamente, en primer lugar, la naturaleza jurídica de los Estatutos de Autonomía a la luz de la STC 31/2010. En segundo lugar, se abordará el papel que el TC se atribuye en la configuración actual del Estado Autonómico. El objetivo final es contribuir a la determinación de la posición de los EEAA en el sistema constitucional tras la STC 31/2010.

5 Cruz Villalón, P., La curiosidad del jurista persa, y otros estudios sobre la Constitución, CEPC, Madrid, 1999, pág. 432.

6 Albertí Rovira, E., «L'Estatut d'Autonomia en el marc de la Constitució», Vint-i-cinc anys d'Estatut d'autonomia de Catalunya: balanç y perspectivas, AA.VV, IEA, Barcelona, 2005, pág. 85.

7 De hecho, de acuerdo con la STC 31/2010, la reserva de ley orgánica afectaba a diversos preceptos del EAC relativos a Derechos Fundamentales, organización local, Poder Judicial, financiación y referéndum.

8 STC 5/1981 $\left(\mathrm{FJ} 21^{\circ}\right)$. 


\section{LOS ELEMENTOS DEFINITORIOS DE LOS ESTATUTOS DE AUTONOMÍAS}

Pese a la importancia que tienen los EEAA se trata de una «fuente del derecho que está insuficientemente construida» ${ }^{9}$. Probablemente la dificultad principal para configurar dogmáticamente esta norma haya sido la diversidad de procedimientos de aprobación y reforma de los EEAA. En otros términos, no hay una correspondencia clara entre norma y procedimiento. Por este motivo se ha acudido a la función constitucional de los EEAA. Ambos elementos, procedimiento y función, se emplean recurrentemente por la doctrina para intentar definir su naturaleza jurídica

No existe un único procedimiento ni de aprobación ni de reforma. Además, con independencia del procedimiento de aprobación y reforma, todos los EEAA ocupan la misma posición en el ordenamiento ${ }^{10}$. La Constitución tan sólo exigía que se aprobaran como ley orgánica ${ }^{11}$, que se celebrase un referéndum si el Estatuto se había aprobado conforme al procedimiento del art. 151.2 CE y que los EEAA regularan su procedimiento de reforma. Esta última previsión dotaba de una elevada garantía al Estatuto de Autonomía. De hecho, aunque hay diversos procedimientos de reforma, las autonomías optaron por conferirle un rol central a sus parlamentos en la reforma.

En consecuencia, aunque en los procesos de aprobación de los EEAA de las «Comunidades de régimen ordinario» la participación de las propias autonomías fuera menor, en la reforma de los EEAA todos los Parlamentos Autonómicos ocupan un lugar cen$\mathrm{tral}^{12}$. Independientemente del organismo que inste la iniciativa, la reforma debe someterse a debate en el Parlamento Autonómico y aprobarse por mayoría cualificada. Por tanto, la iniciativa auténtica es atribuida al Parlamento Autonómico, que la ejerce cuando aprueba una propuesta y la eleva, como proyecto de reforma, a las Cortes Generales. De ahí que pueda afirmarse que, en materia de reforma estatutaria, «corresponde al Parlamento Autonómico el monopolio de la iniciativa legislativa stricto sensu» ${ }^{13}$.

De manera que, si bien no existe un único procedimiento de reforma de los EEAA, sí puede concluirse que se garantiza a la Comunidad Autónoma el mantenimiento de su marco institucional y competencial, ya que sólo podrá alterarse con el concurso de su voluntad o mediante la reforma constitucional. De este modo el principio de autonomía li-

9 Cascajo CAStro, J. L., «Observaciones sobre la denominada función constitucional de los Estatutos de Autonomía», TRC, nº 23, 2009, pág. 136.

10 Trujillo, G., Escritos sobre la estructura territorial del Estado, Senado, Madrid, 2006, pág. 405.

$11 \mathrm{Si}$ bien se trata de una ley orgánica tramitada por un procedimiento especial y no modificable a través de cualquier ley orgánica. SolazÁBAL Echavarría, J. J., «Sobre las reformas estatutarias y la propuesta del Parlamento catalán», La Reforma de los Estatutos de Autonomía, RuIz-Rico RuIz, G. (Cood.), Tirant lo Blanch, Valencia, 2006, pág. 20 Tampoco existe un único procedimiento como ponen de relieve la Resolución de la Presidencia del Congreso de los Diputados de 16 de marzo de 1993 y la Resolución de la Presidencia del Senado de 30 de Septiembre de 1993, sobre el procedimiento a seguir para la tramitación de la reforma de los Estatutos de Autonomía.

12 Solozábal Echavarría, J. J., Las bases constitucionales del Estado autonómico, Mac Graw-Hill, Madrid, 1998 , págs. 140 y ss. 162.

13 Trujillo, G., «La reforma del Estatuto de Canarias: caracterización general», CDP, núm 2, 1997, pág. 
mita la capacidad de intervención de las Cortes Generales ${ }^{14}$ y se erige el Parlamento Autonómico en actor decisivo.

Asimismo, se ha acudido a la función constitucional de los EEAA como parámetro adicional que concreta su lugar en el sistema. En este sentido, no hay discusión alguna acerca del papel que los EEAA jugaron a la hora de configurar el modelo autonómico. Con su aprobación se cerró el mapa autonómico actual y se consagró la naturaleza política de la autonomía de las diecisiete CCAA. Sin embargo, el sistema competencial suscitaba un problema adicional, ya que la Constitución solo establece las competencias estatales, remitiéndose a los EEAA para fijar las competencias autonómicas en cada caso.

La posibilidad de que el sistema competencial difiriera entre CCAA en función de sus EEAA fue minimizada por la jurisprudencia constitucional, que interpretó de manera uniforme los distintos tipos de competencias e incardinó todas las materias en alguno de los títulos competenciales estatales o autonómicos, como pone de relieve que no hiciera uso de la cláusula residual. De este modo, tras las reformas estatutarias de finales de los noventa, el sistema competencial estaba definido y era altamente homogéneo.

$Y$ en este punto surge la segunda dificultad para determinar la posición de los EEAA. Si el sistema competencial está definido, los EEAA ya han cumplido con su función constitucional principal, De manera que, más allá de posibles reformas de mayor o menor entidad, restringidas básicamente al diseño institucional de cada Comunidad, los EEAA no podrían redefinir ni alterar el modelo global. En consecuencia, la función de definir, concretar o modificar los elementos centrales del sistema competencial sólo puede corresponder al TC, siempre y cuando no se lleve a cabo una reforma constitucional ${ }^{15}$.

Es evidente que la reforma del EAC se basa en la idea de que la apertura del modelo autonómico es una característica definitoria del mismo, de manera que el principio dispositivo puede seguir actuando mediante las reformas de los Estatutos ${ }^{16}$. Por tanto, conforme esta propuesta, los Estatutos pueden modificar de manera sustancial y vinculante el sistema autonómico, ya que sus propuestas deberían guiar la jurisprudencia constitucional. En consecuencia, ante la improbable reforma constitucional, la reforma de los EEAA sería la vía más idónea para remodelar el sistema.

La tesis de la deconstitucionalizacion y la apertura del sistema fue defendida por la STC 247/ 2007 a propósito de la reforma del Estatuto de Autonomía de la Comunidad Valenciana. En dicha sentencia el Tribunal situó el centro de gravedad de los posibles límites constitucionales de los EEAA en la fijación de su «contenido constitucionalmente lícito» $\left(\mathrm{FJ} 3^{\circ}\right)$. Sin embargo, no resolvió satisfactoriamente esta cuestión, porque en ningún momento concretó mínimamente dicho contenido. Este hecho dejaba sin respuesta cómo articular la relación entre los EEAA y las leyes orgánicas, en caso de solapamiento.

14 Cascajo Castro, J. L., «La reforma del Estatuto», Estudios sobre el Estatuto de Autonomía del País Vasco, AA.VV., IVAP, Oñati, 1991, pág. 1708.

15 Entre otros, Fernández Farreres, G., ¿Hacia una nueva doctrina constitucional del estado autonómico? (Comentario a la STC 247/2007, de 12 de diciembre, sobre el Estatuto de Autonomía de la Comunidad Valenciana), Cizur Menor, Thomson-Civitas, 2008, págs. 74 y ss.; ORTEGA, L., «Reforma constitucional y reforma estatutaria», De la reforma estatutaria, LÓpez RAMÓN, F. (ed.), Gobierno de Aragón, Zaragoza, 2005, pág. 59.

16 Fossas EsPadaler, E., El principio dispositivo en el Estado autonómico, IVAP/MP, Madrid, 2007, págs. 83 y ss. 
Para resolver este problema el TC recurrió de manera sorpresiva a la diferencia entre eficacia y validez, que permitiría convivir simultáneamente una ley orgánica y un Estatuto de Autonomía con contenidos incluso incompatibles $\left(\mathrm{F} \mathrm{J}^{\circ}\right.$ ). Esta decisión fue duramente criticada $^{17}$, ya que creaba serios problemas de seguridad jurídica, y resultaba contradictoria con un sistema que siempre se ha basado en la delimitación y separación de ámbitos competenciales.

Quizá por dichas críticas la sentencia 31/2010 abandona esta construcción, pero acoge otra, si cabe, más débil ya que no menciona el procedimiento de aprobación y reforma de los EEAA, sino que tan sólo recuerda que son aprobados como leyes orgánicas. De este modo la sentencia reconoce que el verdadero núcleo de la cuestión es la «definición de la función y el contenido propios de los EEAA; su posición (.) y, particularmente, su relación con la Norma Fundamental y con las restantes normas del Ordenamiento» (F. $\mathrm{J} 1^{\circ}$ ), pero no toma en cuenta las variables que podrían permitirle afrontar este reto. De hecho, afirma simplemente que los EEAA se integran bajo la forma de ley orgánica, de modo que «su posición en el sistema de fuentes es, por tanto, la característica de las Leyes Orgánicas» (F. J $\left.3^{\circ}\right)$. La relación entre las restantes leyes orgánicas y los EEAA se articularán conforme a criterios de distribución competencial, en función del contenido.

Esta afirmación podría hacer pensar que está delimitado el espacio que corresponde a las leyes orgánicas, y que éste se ha integrado coherentemente en el sistema autonómico. Sin embargo la jurisprudencia del TC no ha sido ni lineal ni coherente al respecto, siendo un tema no resuelto. El TC mantiene que las leyes orgánicas no suponen un titulo competencial del Estado y, en consecuencia, no amplían el número de las potestades que el art. 149.1 CE le confiere, pero en la práctica actúan como tal.

La mayor prueba de esta naturaleza competencial de la ley orgánica es la STC 173/1998 ya que, incluso no existiendo una ley orgánica sobre el derecho de asociación, el TC consideró que su desarrollo directo estaba reservado a la ley orgánica y, por tanto, la ley del parlamento vasco era parcialmente inconstitucional. A pesar de ello, el TC sigue sin afirmar explícitamente que las leyes orgánicas atraen competencias hacia el Estado en detrimento de las CCAA $^{18}$. Sin embargo, sería más efectivo reconocer que la competencia para aprobar leyes orgánicas le corresponde de facto exclusivamente al Esta$\mathrm{do}^{19}$. Dada la concurrencia de dichas leyes orgánicas con ámbitos reservados en principio a las CCAA, el camino sería una interpretación restrictiva de su alcance, basada la defensa de las competencias autonómicas.

Este carácter de competencia en la praxis de la ley orgánica, debería haberse reflejado en el análisis de constitucionalidad de los preceptos estatutarios que interferían con materias reservadas a ley orgánica, pero particularmente en el reconocimiento de derechos por parte de los Estatutos de Autonomía. Ya que, respecto de la Administración de Justicia y el régimen local el Estado ostenta amplias competencias, gracias a una interpre-

17 Fernández Farreres, G, ob. cit., págs. 11 y ss.

18 La misma STC 31/2010 considera que el Estado no sólo tiene la competencia sobre la autorización de un referéndum autonómico ex Art. 149.32 CE, sino también sobre su establecimiento y regulación en cuanto atañe al desarrollo del Art. 23 CE reservado a la Ley Orgánica (FJ 69).

19 Jiménez Asensio, R., La ley autonómica en el sistema constitucional de fuentes del Derecho, MP, Madrid, 2001, pág. 165. 
tación generosa de los preceptos 149.1.5 y 149.1.18 CE por parte del TC. Asimismo, la Constitución le otorga un papel preferente a la LOFCA a la hora de configurar el sistema de financiación autonómica. Sin embargo, no se da esta circunstancia respecto de los derechos fundamentales, que no cabe integrar en algún titulo competencial estatal.

En este sentido, el Estado sólo ostenta sobre los mismos la potestad de aprobar una ley orgánica, y en su caso las derivadas del siempre complejo art. 149.1.1 CE. La jurisprudencia del TC al respecto varía según el derecho y los títulos competenciales implicados en cada controversia, de manera que el 149.1.1 CE ha actuado como límite, criterio hermenéutico o competencia estatal ${ }^{20}$. Esta realidad confluye con la indeterminación de la reserva de ley orgánica, aumentando la confusión. La apuesta de los EEAA por los derechos obligaba al TC a afrontar de manera definitiva este tema. Sin embargo la respuesta de la STC 31/2010 es absolutamente insatisfactoria

Afirmar que «la ley orgánica de aprobación de un Estatuto de Autonomía no puede regular» el desarrollo de los derechos fundamentales porque tiene «una vigencia territorial limitada», y su «ámbito propio es el de la generalidad, por tratarse de la norma primaria de un sistema normativo autónomo» (FJ 17), es un subterfugio para, en la praxis, negar toda virtualidad a algunos artículos del Estatuto. En este sentido, si bien acepta que los Estatutos reiteren o mencionen derechos reconocidos en la Constitución, la ley de desarrollo ha de ser en diversos supuestos una ley estatal, orgánica u ordinaria. De esta manera admite que puedan ser derechos subjetivos ${ }^{21}$, evita la declaración de inconstitucionalidad, pero los preceptos estatutarios quedan reducidos a reiteraciones de derechos reconocidos en la Constitución, que han de ser desarrollados en algunos casos por el legislador estatal. El resultado no podría ser más rocambolesco

El TC podía haber seguido dos caminos muy diferentes pero coherentes. Por un lado, podía haber declarado inconstitucional todas las regulaciones de derechos por parte de las Comunidades Autónomas sobre las materias en las que ostenta competencias el Estado. Entre las cuales cabe incluir las reservadas a las leyes orgánicas, o a títulos competenciales como el art. 149.1.30 o, incluso, el 149.1.1 CE. Esta declaración debía partir de una comprensión realmente restrictiva del elemento material de las leyes orgánicas y de las competencias estatales. En este sentido, se trataría de considerar que el constituyente reservó al Estado la regulación de un amplio espacio respecto de los derechos. Sería una interpretación, además, completamente coherente con la consideración del Estatuto de Autonomía como ley orgánica de ámbito territorial limitado y contenido necesariamente general. Al ser imposible su degradación, imponerse una interpretación especialmente restrictiva de su contenido como consecuencia del principio democrático, y renunciar al binomio validez- eficacia, el único resultado consecuente parece la nuli$\mathrm{dad}^{22}$.

20 Al respecto, González Pascual, M., El proceso autonómico frente a la igualdad en el ejercicio de los derechos constitucionales, IVAP, Oñati, 2007.

21 Aunque la sentencia relativa al Estatuto de Autonomía de la Comunidad Valenciana rechazó que los derechos estatutarios pudieran ser derechos subjetivos 247/2007 (FJ 15\%).

22 Esta es la lógica seguida por AGUADo RENEDo, C., «De nuevo sobre la naturaleza jurídica del Estatuto de Autonomía, con motivo de los procesos de reforma", Revista parlamentaria de la Asamblea de Madrid, $\mathrm{n}^{\circ} 17$, 2007 págs. 303-304. 
Por el otro, podía haber tomado en consideración que, conforme al art. 37.1 EAC, los destinatarios de los derechos reconocidos en el EAC son los poderes autonómicos, salvo en los casos de los arts 32 y 33 EAC, que también vincularían a la Administración General del Estado. Este camino obliga a analizar si los diferentes artículos del Estatuto que reconocen derechos contradicen o no la Constitución. En lugar de considerar que preceptos tan polémicos como el art. 20 o el 21.2 EAC son compatibles con la Constitución y con la reserva de ley orgánica, porque no añaden nada y, además, en el caso del art. 20 EAC su contenido será desarrollado por el legislador estatal, el TC debería haber reconocido que estos artículos recogen un modelo de educación pública laica y, posiblemente, el derecho a la eutanasia pasiva en una Comunidad Autónoma. Aceptar abiertamente esta realidad implicaba analizar si es o no constitucional, es decir, determinar en primer lugar si se están introduciendo dichos derechos, en segundo si los arts 27, 16 y 15 CE dan cabida a dicha opción. Y, por último, si dichas decisiones no forman parte de las competencias estatales ex arts. 81, 149.1.1, 149.1 .16 y 149.1.30 CE. Este camino habría resuelto dudas fundamentales de la doctrina y, además, habría sido más respetuoso con la función constitucional de los EEAA.

De hecho, resulta sorprendente que la sentencia no haga referencia alguna al procedimiento de reforma de los EEAA, dejando a un lado la participación del Parlamento Autonómico y la celebración de un referéndum. Ambos elementos deberían considerarse absolutamente centrales para la definición de los EEAA. La Constitución no quiso que los EEAA fueran leyes orgánicas especiales por su contenido, de hecho las leyes orgánicas se derogan y modifican entre si. Sin embargo, ninguna ley orgánica puede modificar un Estatuto, como no puede reformar los Tratados aprobados por la vía del art. 93 CE. El art. 147.2 CE establece que el procedimiento de reforma de los EEAA debe fijarse en el mismo Estatuto, siendo una garantía de la posición de los mismos y, por ende, de la autonomía política. Autonomía política que es un reflejo del principio democrático. Por eso los Estatutos que permitían el nacimiento y configuración de Comunidades Autónomas con Asambleas Parlamentarias debían establecer su propia reforma y esta, en todo caso, exigía no solo una ley orgánica sino, también, un referéndum ${ }^{23}$.

La paradoja de la sentencia es que solo toma en cuenta este procedimiento para advertir de los riesgos de una petrificación del ordenamiento ${ }^{24}$. De manera que el procedimiento

23 De ahí que se haya defendido que todos los EEAA deberían prever la necesidad de referéndum para llevar a cabo su reforma como «estadio obligado en la evolución del Estado Autonómico». Gutiérrez Llamas, A., Los procedimientos para la reforma de los Estatutos de Autonomía de las Comunidades Autónomas, Civitas, Madrid, 1991, pág. 156. Es evidente que en los orígenes del Estado Autonómico podía justificarse un diferente grado de participación de las autonomías y del electorado en la elaboración y aprobación del Estatuto, pero esta dualidad perdió su sentido hace tiempo. De hecho, se prevé la convocatoria de referéndum para las futuras reformas de los Estatutos de Autonomía de la Comunidad Valenciana (Art. 81) y Aragón (Art. 115), así como en la propuesta de reforma del Estatuto de Autonomía de Extremadura (Art. 91) y en las fallidas propuestas de reforma de los Estatutos de Autonomía de Castilla La Mancha (Art. 170) y Canarias (Art. 163).

24 Ya que su elevada rigidez, "puede llegar a no compadecerse con un efectivo derecho a la participación politica en el ejercicio de los poderes estatuidos.» (FJ $6^{\circ}$ ) Esta información es particularmente relevante respecto del EAC ya que tiende a la exhaustividad y minuciosidad en sus más de 200 preceptos. Aunque el TC tan solo recurre a la rigidez del procedimiento de reforma Estatuto como criterio a mayor abundamiento para declarar parcialmente inconstitucional el art. $111 \mathrm{EAC}\left(\mathrm{F} . \mathrm{J} 60^{\circ}\right.$ ). De manera que el contenido de los EEAA sigue sin estar delimitado y carece de utilidad práctica. 
de reforma estatutaria, hecho a medida del reconocimiento de la autonomía política en nuestro sistema constitucional, juega «en contra» del Estatuto careciendo de cualquier otro papel.

Asimismo, la sentencia cita el bloque de la constitucionalidad, pero no parece deducir efectos jurídicos tangibles ${ }^{25}$. La función del Estatuto se remite a «la creación de sistemas normativos autónomos» y «a garantizar la indemnidad de dichos sistemas», asimismo dota de competencias a la Comunidad y es su norma institucional básica. Ahora bien, toda vulneración del Estatuto de Autonomía, es inconstitucional en la medida en que sea vulneración de la Constitución. Ya que «la Constitución es la única norma capaz de atribuir (.) la competencia necesaria para la producción de normas válidas» $\left(\mathrm{FJ} 4^{\circ}\right)$.

Esta eliminación en la práctica del bloque de constitucionalidad es meridiana cuando el TC afirma su competencia para la «definición auténtica e indiscutible» de las categorías y principios constitucionales, competencia que no pueden usurpar «las normas infraconstitucionales», entre las que sitúa a los EEAA (FJ 57). Cualquier posibilidad de categorizar a los EEAA como normas constitucionales secundarias o leyes constitucionales es, de facto, rechazada por la sentencia. Ya que dicha conceptualización se fundamentaba en su procedimiento de reforma, su rango superior a las demás normas, ordinarias u orgánicas, y en su función como medida de la validez de las leyes del Estado ${ }^{26}$.

$\mathrm{Y}$, sin embargo, tomar como punto de partida el procedimiento de aprobación y, de reforma de los EEAA, así como la función que cumplen, no habría impedido su sumisión a la Constitución y al TC. Pero habría permitido una determinación y configuración del modelo territorial más acorde a la realidad constitucional que tomar como único elemento de relieve la aprobación bajo la forma de ley orgánica.

Ahora bien, el TC en el fondo no equipara a los EEAA con las leyes orgánicas. Es evidente que si hubiera llevado hasta sus últimas consecuencias la afirmación de que los EEAA son leyes orgánicas territorialmente limitadas, la consecuencia irremediable habría sido la declaración de nulidad de muchos más preceptos ${ }^{27}$. Esta decisión habría partido de una visión absolutamente errónea del sistema autonómico, pero habría sido consecuente, ya que el resultado se habría correspondido con las premisas teóricas de la sentencia. Sin embargo la sentencia busca de manera denodada la declaración de constitucionalidad del Estatuto de Autonomía, en ocasiones mediante interpretaciones de los artículos que contradicen su tenor literal ${ }^{28}$ o que los reducen a meros desiderátum de las autonomías ${ }^{29}$.

En otras ocasiones parece latir una concepción menos restrictiva del Estatuto de Autonomía y un reconocimiento cauto de su función constitucional. En este sentido, hay que subrayar que los artículos relativos a la participación de la Comunidad Autónoma en

25 Tornos Mas, J., «L'Estatut com a norma jurídica», RCDP, 2010, pág. 3.

26 Rubio Llorente, F., «El bloque de constitucionalidad», REDC, n 27, 1989, págs. 25-26.

27 De hecho el voto particular del magistrado Delgado Barrio parte de la consideración de los EEAA como leyes orgánicas de alcance territorial limitado y, efectivamente, considera que deberían haberse declarado inconstitucionales bastantes más preceptos.

$28 \mathrm{Al}$ respecto un ejemplo sangrante es que el Tribunal Constitucional considere que las veguerías tan sólo implican un cambio a la denominación de las provincias, siendo que todas las competencias sobre éstas corresponde al Estado, o que son una entidad local nueva, no sustituyendo a las Diputaciones. (FJ $41^{\circ}$ ) Esta lectura contradice claramente el Art. 91 EAC.

29 Uno de los múltiples ejemplos es la afirmación de que el deber de los Registradores y Notarios de acreditar el conocimiento del derecho catalán «no deja de ser una legítima pretensión del legislador estatutario (.) que debe ser instrumentada por el legislador con plena libertad» $\left(\mathrm{FJ} 90^{\circ}\right)$. 
la UE, y la acción exterior son declarados constitucionales. De este modo parece aceptar la decisión de compensar mediante las reformas de los Estatutos las deficiencias del sistema constitucional respecto de los mecanismos de colaboración y participación de las Autonomías en decisiones que les atañen. Aunque al respecto simplemente afirma que el "Estatuto de Autonomía no es una sede normativa inadecuada», expresión absolutamente vacua que nada aporta al debate constitucional.

De manera que, pese a reconocer que la definición de la función, contenido, posición y relación con el resto del ordenamiento del Estatuto, constituye el elemento esencial para valorar la constitucionalidad del EAC, la sentencia arroja más sombras que luces al respecto. Parece que el TC, ante la incapacidad para formular una teoría coherente, toma como punto de referencia la aprobación de los EEAA mediante leyes orgánicas, cometiendo con esta decisión dos errores.

En primer lugar olvida que su propia jurisprudencia no tiene un concepto claro de la ley orgánica ${ }^{30}$. Pero, en segundo lugar, olvida que cuando los TC se ven enfrentados a un problema que precisa una respuesta general y estabilizadora, como sin duda es la determinación de la naturaleza de un Estatuto de Autonomía, dicha respuesta no puede ser tan complicada como las preguntas que se plantean, pero tampoco tan sencilla que no abarque la problemática global del campo jurídico en el que actúa ${ }^{31}$. Este es el mayor error de la sentencia, el TC no incardina su decisión en el complejo entramado del sistema autonómico demostrando su incapacidad para afrontar el reto que se le presentaba.

De este modo elude las preguntas dogmáticas de calado, y contesta de manera sorpresiva e, incluso, inconexa ${ }^{32}$ a las decenas de cuestiones que en el recurso se planteaban. Para ello acude a categorías que distan de estar claras o que son muy cuestionadas, pero que le confieren una aparente seguridad porque parecen no precisar ulteriores argumentaciones en su discurso. Para encontrar esta falta de seguridad perdida, la sentencia evoca al Tribunal que configuró el Estado autonómico como si la evolución del sistema y las reformas que se pretenden no pudieran afectarle. No en vano, al carecer de una idea clara de clara del papel y la posición que los EEAA ocupan en el sistema, el TC sólo puede apoyarse en una Constitución que sobre las autonomías apenas dice nada, de manera que en realidad tan sólo le queda su propia jurisprudencia.

\section{EL PAPEL DE LA JUSTICIA CONSTITUCIONAL EN EL SISTEMA AUTONÓMICO}

Es un lugar común poner de relieve el papel absolutamente central que el TC ha desempeñado en la configuración y evolución del Estado Autonómico. Una Constitución incompleta y mayormente transitoria en lo que a configuración territorial se refiere, una re-

30 Chofre Sirvent, J. F., Significado y función de las leyes orgánicas, Tecnos, Madrid, 1994, pág. 130.

31 Jarass, H. J., «Bausteine einer umfassenden Grundrechtsdogmatik», AöR, 1995, págs. 346-347.

$32 \mathrm{Al}$ respecto basta recordar que el art. 97 EAC preveía la creación de un Consejo de Justicia como órgano desconcentrado del CGPJ. El TC considera que dicha posibilidad es inconstitucional, pero lejos de declarar nulos todos los artículos al respecto, afirma que el Consejo de Justicia es un órgano autonómico especifico, y deja intactas algunas de las potestades que el EAC otorgaba a un órgano cualitativamente diferente (FFJJ $\left.47-48^{\circ}\right)$. 
gulación dispersa y excesivamente heterogénea, la falta de acuerdo político para una construcción global y coherente de un sistema que se ha ido conformando sobre la base de impulsos políticos, un conflicto latente entre algunos de los principales actores, y la imposibilidad de una imprescindible reforma constitucional, son algunos de los factores que han convertido al Tribunal Constitucional en un sujeto más del Estado Autonómico ${ }^{33}$.

Su papel fue decisivo y, durante las primeras décadas, altamente satisfactorio. Aunque algunas de sus líneas jurisprudenciales fueran puntualmente criticadas, en términos generales la doctrina del TC era su principal fuente de legitimidad. Sin embargo, este continuo recurso a la Justicia Constitucional pretendía rellenar el hueco que debía ocupar el acuerdo entre el Estado y las CCAA, acuerdo clave para la fijación de las competencias y actuaciones de cada una de las partes. Por eso, la construcción del sistema por la jurisprudencia ha acabado generando dos problemas de naturaleza diversa que concurren en la sentencia 31/2010.

De una parte, la intervención de los Tribunales en las decisiones sobre el reparto último del poder puede dañar su propia posición en el sistema, tal y como ha ocurrido en el caso del Tribunal Constitucional ${ }^{34}$. De la otra, una labor interpretativa excesiva de la jurisprudencia acaba convirtiendo un marco normativo abierto al debate y los acuerdos entre los actores democráticos, en una exhaustiva y detallada lista de reglas específicas que no sólo impide el debate, sino que crea la ficción de ser una realidad incontestable ${ }^{35}$. El mejor ejemplo de este segundo problema posiblemente sea el alcance que el TC otorga a la reforma del sistema competencial que proponía el EAC.

Una de las grandes apuestas del EAC era una readaptación del sistema constitucional de competencias. Como ha sido suficientemente comentado por la doctrina, el EAC en realidad intentaba «blindar» las competencias autonómicas fundamentalmente mediante la cita exhaustiva de las submaterias sobre las que la Comunidad Autónoma ostenta la competencia, y la redefinición de los binomios bases-desarrollo y legislación-ejecución $^{36}$. El propósito era promover una nueva jurisprudencia del TC sobre dichas cuestiones que favoreciera un mayor alcance de las competencias autonómicas.

De hecho, la jurisprudencia del TC relativa al sistema de competencias ha sido objeto de críticas recurrentes. Con frecuencia se pone de relieve que la comprensión generosa de los títulos competenciales estatales horizontales, las excesivas excepciones al elemento formal de lo básico y la aceptación de normativa detallada al respecto, así como la limitación de las competencias de ejecución a los reglamentos organizativos, suponen una continua pérdida de competencias por parte de las CCAA. Asimismo esta comprensión del sistema de competencias se refleja en las competencias sobre la ejecución del derecho de la UE, constriñendo aún más las potestades autonómicas.

33 López Guerra, L., «El futuro del Estado de las Autonomías», CDPb, no 32, 2007, págs. 14-15.

34 A pesar de la importancia que tiene para el sistema constitucional la incuestionable erosión que la legitimidad del TC ha sufrido a raíz de la interposición del recurso de inconstitucionalidad contra el EAC, su valoración excede este análisis.

35 WaHL, R., «Der Vorrang der Verfassung», Der Staat, 1981, pág. 507.

$36 \mathrm{Al}$ respecto, AlberTí Rovira, E., «El blindatge de les competències i la reforma estatutària», RCDP $\mathrm{n}^{\circ}$ 31, 2007, Tornos Mas, J., «Balance de la distribución de competencias tras la reforma de los Estatutos de Autonomía», Informe comunidades autónomas 2006, AA.VV., IDP, Barcelona, 2007. 
Por ello la doctrina ha señalado la oportunidad de reforzar el elemento formal de lo básico, minimizar la posibilidad de legislación detallada, usando para ello la propia diferenciación constitucional entre bases, legislación básica y normas básicas. También se ha defendido que se sigan criterios formales para la delimitación de las competencias sobre la legislación, que se tenga en cuenta la realidad de la UE a la hora de interpretar los respectivos ámbitos competenciales y, por último, que se lleve a cabo una lectura restrictiva de los títulos competenciales horizontales.

En otros términos, la propuesta del EAC partía de una necesidad compartida por gran parte de la doctrina. Asimismo, el Estatuto de Autonomía de Andalucía llevaba a cabo una propuesta similar. Además tanto los nuevos Estatutos de Autonomía de Aragón, Islas Baleares, Castilla y León, Comunidad Valenciana y Navarra, como las propuestas de reforma de Castilla-La Mancha, Canarias y Extremadura, han buscando incrementar las competencias autonómicas ampliando sus listados originales al respecto. $\mathrm{Si}$ se tiene en cuenta el procedimiento de aprobación de las reformas de los EEAA, y su función como parte del bloque de constitucionalidad, es evidente que existía un amplio consenso acerca de la necesidad de aumentar las potestades autonómicas.

Frente a este consenso, y a los años de crítica doctrinal, el TC simplemente recuerda la STC 76/1983 y afirma su potestad, única y excluyente, para interpretar el sistema constitucional. La cita a una sentencia aprobada en los orígenes del Estado Autonómico respecto de una ley de armonización, sirve para dinamitar en la praxis las aspiraciones autonómicas de un mayor espacio competencial. De una manera lacónica asume la idea de que el EAC es una «LOAPA invertida» ${ }^{37}$, en contra incluso de su jurisprudencia más reciente $^{38}$. Pero tanto su esquema argumentativo como sus conclusiones son el resultado de dos premisas básicas falsas.

La primera es que únicamente el Tribunal Constitucional interpreta la Constitución. Al TC le corresponde tomar la decisión en último término, pero las interpretaciones de los restantes actores constitucionales deben ser escuchadas, y eso implica ser discutidas cuando van a ser rechazadas. En este caso, se trataba de una norma que forma parte del bloque de constitucionalidad y que había sido aprobada por las Cortes Generales, por una elevada mayoría en el Parlamento Autonómico, y que fue sometida a referéndum. La legitimación de la jurisprudencia mediante la fuerza de sus argumentos jurídicos posiblemente nunca antes fue tan necesaria en una sentencia del TC español. La cita de la STC 76/1983 no es suficiente, máxime cuando dicha sentencia fue criticada precisamente porque entronizaba al TC como el único interprete válido del sistema constitucional ${ }^{39}$.

37 Ortega, L., ob. cit., págs. 64 y ss.

38 La Sentencia 247/2007 también cita la STC 76/1983 pero con consecuencias muy diferentes (FF. J $7^{\circ}$ $\left.10^{\circ}\right)$. De hecho, se afirmaba que posiblemente el TC estaba sentando las bases para que las previsiones del EAC fueran constitucionales. Fernández FArreres, G, ob. cit., págs. 56 y ss. TORnOS MAs, J., «La sentencia del Tribunal Constitucional 247/2007 y el sistema constitucional de distribución de competencias entre el Estado y las Comunidades Autónomas», REAF, n 7, 2008, págs. 96 y. ss. Ciertamente no se juzgaban los preceptos del EAC, pero este aparente giro jurisprudencial sorpresivo redunda en la insuficiente argumentación del TC en la STC 31/ 2010.

39 Cruz Villalón, P., «¿Reserva de Constitución? Comentario al Fundamento Jurídico Cuarto de la Sentencia del Tribunal Constitucional 76/1983, de 5 de agosto, sobre la LOAPA», REDC, 1983, núm 9, pág. 208. 
La segunda premisa falsa, consecuencia de la anterior, es que la interpretación de las competencias se rige por una lógica jurídica evidente, de manera que los títulos competenciales son silogismos a concretar y aplicar por los técnicos del derecho, sin consideraciones valorativas. Sin embargo, en los Estados descentralizados la división de potestades depende más de cuestiones políticas que de prescripciones constitucionales ${ }^{40}$. Las competencias deben ser dotadas de estabilidad, ya que son la premisa de la actuación del poder público y de su claridad depende la eficiencia del sistema en su conjunto. Pero también son flexibles, y se adaptan a los continuos movimientos de poder que los actores políticos puedan decidir. En caso de disputa entre dichos actores, los Tribunales toman una decisión vinculante pero sobre la base de los acuerdos que hayan podido adoptar los actores legitimados para ello.

En la STC 31/2010 no se tiene en cuenta el desarrollo constitucional del Estado Autonómico. Sin embargo, no sólo hay una ingente jurisprudencia respecto del Estado Autonómico, también ha tenido lugar un intenso desarrollo institucional, una clarificación y consolidación de los actores políticos centrales, un reforzamiento de la conciencia ciudadana de autogobierno, y un proceso europeo de innegables consecuencias para las autonomías. A la propuesta de un Estatuto de Autonomía en la actualidad no puede contestarse citando una jurisprudencia elaborada al hilo de una norma de diferente cualidad que se aprobó en un contexto muy distinto.

El TC tenía que haber reconocido las críticas a su doctrina, defender la pertinencia de su interpretación para el correcto desarrollo del Estado Autonómico en el momento actual, exponiendo con claridad las razones para ello, rebatir de manera ordenada y exhaustiva los argumentos de los recurrentes y aplicar después estas consideraciones a los restantes artículos relativos a las competencias que fueron recurridos. En definitiva, tenía que haber fundamentado su postura de una manera convincente, con un discurso coherente, actual, y razonado mostrando una disposición al diálogo con los actores implicados ${ }^{41}$.

No en vano, tomar en consideración una petición democrática es un deber constitucional $^{42}$. El TC debía resolver el recurso de inconstitucionalidad planteado frente a una norma que, no sólo ha seguido un complejo procedimiento de reforma, sino que refleja que la Comunidad Autónoma de Cataluña considera necesaria una modificación profunda del Estado Autonómico treinta años después de la aprobación de su Estatuto de Autonomía. Por ello, la sentencia debía mostrar que el TC era plenamente consciente de esta circunstancia teniéndola en cuenta explícitamente a la hora de construir su argumentación

Ahora bien, estas consideraciones no implican que el TC tuviera que considerar que todos los preceptos del EAC eran constitucionales. Precisamente la Justicia Constitucional se caracteriza por sus competencias frente al legislador democrático. De hecho, el

40 BurCA, G., «Limiting EU Powers», EuConst, 2005, 1, pág. 94.

41 Sin embargo, sorprendentemente el TC considera que dada «la exhaustividad con la que en los antecedentes se ha dado cuenta de las posiciones de las partes» no es necesario que en los fundamentos jurídicos haga más referencias a las razones de las mismas, «siendo suficiente con la indicación de los antecedentes en los que se hayan reseñado las respectivas posiciones» $\left(\mathrm{FJ} 1^{\circ}\right)$.

42 Cruz Villalón, P., «La reforma...», ob. cit., pág. 91. 
sistema competencial propuesto por el EAC planteaba una serie de problemas que la sentencia habría tenido que afrontar, de haber optado por un examen riguroso del mismo. En primer lugar, de haberse aceptado esta nueva interpretación tendría que haberse aplicado a las competencias estatales respecto del conjunto de las CCAA, ya que sería ingobernable mantener diecisiete sistemas competenciales. Otra solución sería simplemente absurda.

En segundo lugar, aunque es necesario que los títulos competenciales horizontales sean interpretados restrictivamente, las competencias exclusivas no pueden dominar el sistema ${ }^{43}$. En otros términos, sin cláusulas que dinamicen el sistema y la asunción de un cierto solapamiento y movimiento inevitable de las potestades, el sistema se bloquea. Ante la falta de acuerdo político, se acude con frecuencia a los sistemas competenciales de separación frente a los de cooperación, pero los primeros han sido siempre han sido ineficaces en la praxis y, además, nunca se han alcanzado completamente. El listado de submaterias del EAC no toma en cuenta dicha realidad ${ }^{44}$ y cercena la capacidad de adaptación del sistema si se hace una lectura literal del mismo. No puede olvidarse que rara vez las cuestiones competenciales se resuelven mediante un listado de materias ${ }^{45}$.

En tercer lugar, la experiencia de otros sistemas pone de relieve que teóricamente se puede afirmar que las competencias compartidas otorgan la potestad para aprobar principios generales o normas que no sean de aplicación directa, pero dicha conceptualización ha acabado con la desaparición de la categoría normativa afectada o con la aceptación de continuas excepciones ${ }^{46}$. Dado el carácter absolutamente central de la normativa básica en nuestro sistema, la lógica acabaría siendo la dinámica actual de excepciones continuas. En definitiva, la diferenciación del alcance de las bases en función de la materia, la limitación de la normativa detallada, y el reforzamiento del elemento formal son, a mi juicio, parámetros razonables y con perspectivas de éxito. Otros criterios probablemente mantendrían el sistema en unas coordenadas tan disfuncionales como las actuales.

Por tanto, el TC disponía de argumentos convincentes para discutir la reforma, hacer entender la imposibilidad de su puesta en funcionamiento hasta sus últimas consecuencias e, incluso, haber mantenido sustancialmente su doctrina. Lejos de este camino sencillamente niega la posibilidad de que un Estatuto de Autonomía coadyuve a la definición de los conceptos competenciales. De este modo declara inconstitucional la previsión de que las bases sean principios o mínimo común normativo en normas con rango de ley, mantiene la identificación de la «ejecución» con los reglamentos de organización interna, y neutraliza los efectos que el Estatuto le otorgaba a las competencias autonómicas exclusivas. Este hecho mantiene sin cambios el sistema constitucional competen-

43 Nettesheim, M., «Die Kompetenzordnung im Vertrag über eine Verfassung für Europa», EuR, 2004 , pág. 533.

44 SolozÁbal Echavarría, «Algunas consideraciones sobre las reformas estatutarias», TRC, $\mathrm{n}^{\circ} 22$, 2008, págs. 324-325.

45 MAYER, F., «Die drei Dimensionen der Europäischen Kompetenzdebatte», ZäöRV, 2001, pág. 613.

46 Esa ha sido la evolución seguida por las leyes marco en el sistema alemán ya que en la reforma de 1994 se intentó limitar su alcance, de manera que solo contuvieran principios generales que no fueran de aplicación directa. Dicha reforma no fructificó, motivo por el cual en la reforma constitucional del 2006 se derogó el Art. 75 LFB desapareciendo las leyes marco del sistema. Al respecto, GonZÁlez PASCUAL, M., «Un sistema competencial multinivell: L'adaptació del sistema competencial alemany al procés comunitari», REAF, $\mathrm{n}^{\circ} 9$, 2009, págs. 179 y ss. 
cial, ya que el Tribunal proyecta estas declaraciones sobre el resto del articulado e, incluso, lleva a cabo una interpretación altamente discutible, cuando no contra legem de algunos preceptos ${ }^{47}$.

Así, aunque las declaraciones de inconstitucionalidad de la sentencia tan solo afectan a catorce artículos, el sistema que había diseñado el Estatuto se desmorona. El Tribunal impone su jurisprudencia relativa al reparto competencial al estatuyente sin analizar seriamente la propuesta del mismo, sin discutir sus ventajas o inconvenientes y, por supuesto, sin modificar mínimamente su propia construcción. Podría concluirse que las reformas de los últimos años apenas han modificado el sistema.

Dejando a salvo cuestiones institucionales y la posible inclusión de nuevas competencias de diverso calado ${ }^{48}$, las previsiones de los EEAA dependerán en gran medida de las futuras decisiones del Estado. Para ello no era preciso reformar los EEAA. Asimismo, al ser muy improbable que finalmente se produzca una reforma constitucional, el Tribunal Constitucional se erige en el pilar central del Estado Autonómico. De hecho la misma sentencia alude en diversas ocasiones a ese papel futuro del Tribunal. Sin embargo, reclama dicho papel como si su posición fuera incuestionable, olvidando que la argumentación es la única herramienta válida de la que dispone la Justicia Constitucional ante decisiones con tanto calado político y social.

La STC 31/2010 puede convertirse, sin duda, en una de las decisiones más importantes del desarrollo del Estado Autonómico, pero no por sus argumentos sino por sus consecuencias. La propuesta del EAC queda fuertemente transformada y sus aspiraciones recortadas, particularmente mediante enrevesadas declaraciones interpretativas que no siempre se llevan al fallo ${ }^{49}$. No confiere estabilidad, porque en algunos puntos hace ininteligibles las opciones del legislador ${ }^{50}$, hecho que provocará nuevos recursos frente a las leyes que desarrollen el EAC. Tampoco su construcción teórica sobre la posición de los EEAA en el sistema podrá ser de ayuda porque, de mantenerla sin matices, anulará el bloque de constitucionalidad. Los EEAA quedan relegados a la estricta configuración del sistema institucional y normativo de las CCAA, ya que el resto de su articulado parece contener tan solo propuestas legítimas sin eficacia jurídica. De este modo, tras esta sentencia, solo disponemos de una Constitución absolutamente ambigua e insuficiente y de una jurisprudencia cada día más cuestionada, para afrontar una cuestión territorial que, por más que nos pese, sigue sin ser resuelta ${ }^{51}$.

$47 \mathrm{Al}$ respecto es un ejemplo palmario que el TC afirme que el Art. 129 EAC no atribuye una competencia general a la Comunidad Autónoma en materia de derecho civil (FJ $76^{\circ}$ ), cuando ese es el propósito evidente del precepto.

48 Así destacan las competencias sobre policía y fuerzas de seguridad previstas en los Estatutos de Autonomía de Andalucía (Art. 65), Aragón (Art. 76), Islas Baleares (Art. 33), Comunidad Valenciana (Art. 55.2) y Castilla León (Art. 72).

49 Como ponen de relieve los votos particulares de los magistrados Conde Martín de Hijas, Delgado Barrio, Rodríguez-Zapata y Ramón Rodríguez Arribas.

50 Un ejemplo claro es la interpretación del Art. 50.5 EAC, de manera que «las entidades públicas t.f pueden utilizar la lengua catalana con normalidad (.) en sus comunicaciones con los particulares, siempre que se arbitren los mecanismos pertinentes para que el derecho de los ciudadanos a recibir tales comunicaciones en castellano pueda bacerse efectivo sin formalidades ni condiciones que redunden para ellos en una carga u obligación que les constituya en la posición de sujeto activo en sus relaciones con la Administración pública» (F. J. $23^{\circ}$ ).

51 Cruz Villalón, P., «La reforma..», ob. cit., pág. 98. 
$* * *$

Title: The position of the Estatutos de Autonomia within the constitutional system. (A commentary of the Constitutional Court decision 31/2010, 28 June 2010).

ABSTRACT: This work analyses the position of the Estatutos de Autonomia within the constitutional system that the Constitutional Court ruled in the Spanish Constitutional Court decision 31/2010. This issue is essential to the future of the Estado Autonómico. For this reason in this work are studied both the legal nature of the Estatutos de Autonomia accoding to their enactment and reform process, and the function of the Estatutos de Autonomía as part of the bloque de constitucionalidad. This study contributes to draw an outline of the main characters and of the concept of the Estatuto de Autonomia, which the Spanish Constitutional Court decision 31/2010 lacks. After that the work analyses from a critical point of view both the role that the Constitutional Justice have to fulfil regarding the configuration of the State and the role that the decision establishes to it. The forecasts are discouraging. The constitutional case law and the Estatutos de Autonomia are essentials to the right development of the State but the Spanish Constitutional Court decision STC 31/2010 removes their potentiality and the capability to face this fact.

RESUMEN: El presente trabajo analiza la posición que el Tribunal Constitucional confiere a los Estatutos de Autonomía en la STC 31/2010, cuestión clave para el futuro del Estado Autonómico. Con dicho fin se estudia la naturaleza jurídica de los Estatutos de Autonomía de acuerdo con su procedimiento de aprobación y reforma, así como su función en cuanto parte del bloque de constitucionalidad. Dicho estudio se contrapone a la carencia de perfiles propios que los Estatutos tienen en la STC 31/2010. Posteriormente se aborda críticamente el papel que la Justicia Constitucional ha de desempeñar en el Estado Autonómico, así como el que se atribuye en la sentencia. Las previsiones tras la sentencia son desalentadoras. La jurisprudencia constitucional y los Estatutos de Autonomía son imprescindibles para el correcto desarrollo del Estado Autonómico, pero la STC 31/2010 elimina la potencialidad y aptitud de los mismos para afrontar dicho reto.

Key Words: «Estatutos de Autonomía». Constitutional Court. Leyes Orgánicas. Allocation of Powers.

Palabras Clave: Estatutos de Autonomía, Tribunal Constitucional, Leyes Orgánicas, Competencias

FECHA DE RECEPCIÓN:28.12.2010. FECHA DE ACEPTACIÓN: 26.01.2011

UNED. Teoría y Realidad Constitucional, núm. 27, 2011, pp. 503-518. 